\title{
Chelated Minerals for Poultry
}

\section{Author(s)}

Vieira SL

Department of Animal Science of the Federal University of Rio Grande do Sul, Porto Alegre, RS, Brazil

\section{Mail Address}

\section{Sergio Luiz Vieira}

Faculdade de Agronomia - UFRGS

Av. Bento Gonçalves, 7712

91540-000. Porto Alegre, RS, Brazil

Phone/Fax: +55 5133087419

E-mail: slvieira@ufrgs.br

\section{Keywords}

Broiler, chelated mineral, organic mineral, poultry

\section{ABSTRACT}

Organic minerals have been subject of an increasing number of investigations recently. These compounds can be considered the most significant event regarding commercial forms of minerals targeting animal supplementation in the last decades. Minerals, especially metals, are usually supplemented in poultry feeds using cheap saline sources and have never required a lot of attention in terms of quality. On the other hand, definitions of organic minerals are very broad and frequently lead to confusion when decision-making becomes necessary. Organic minerals include any mineral bound to organic compounds, regardless of the type of existing bond between mineral and organic molecules. Proteins and carbohydrates are the most frequent candidates in organic mineral combinations. Organic fraction size and bond type are not limitations in organic mineral definition; however, essential metals (Cu, $\mathrm{Fe}, \mathrm{Zn}$, and $\mathrm{Mn}$ ) can form coordinated bonds, which are stable in intestinal lumen. Metals bound to organic ligands by coordinated bonds can dissociate within animal metabolism whereas real covalent bonds cannot. Chelated minerals are molecules that have a metal bound to an organic ligand through coordinated bonds; but many organic minerals are not chelates or are not even bound through coordinated bonds. Utilization of organic minerals is largely dependent on the ligand; therefore, amino acids and other small molecules with facilitated access to the enterocyte are supposed to be better utilized by animals. Organic minerals with ligands presenting long chains may require digestion prior to absorption. After absorption, organic minerals may present physiological effects, which improve specific metabolic responses, such as the immune response. Many studies have demonstrated the benefits of metal-amino acid chelates on animal metabolism, but the detection positive effects on live performance is less consistent.

\section{INTRODUCTION}

Inorganic and organic mineral forms are found in animal tissues, both in variable concentrations. Inorganic elements are found in the ash left after combustion of live tissues mostly as oxides, carbonates, and sulfates (Underwood e Suttle, 1999). Out of the 109 known elements, 26 are considered essential for animals (Underwood, 1977). From these, 11 are macro elements (carbon, hydrogen, oxygen, nitrogen, sulfur, calcium, phosphorus, potassium, sodium, chlorine, and magnesium) and 15 are microelements (iron, zinc, cupper, manganese, nickel, cobalt, molybdenum, selenium, chromium, iodine, fluorine, tin, silicon, vanadium, and arsenic).

The presence of a mineral in animal tissues does not imply its essentiality. Minerals can be natural contaminants and, in this case, they follow a similar distribution as that found in the surrounding 
environment. Essential elements, however, exist in a normal and expected symmetry, and their deficiency results in impairment or loss of organic functions (Uderwood, 1977). The presence of essential elements in animal tissues follows cell function and, therefore, they have typical concentrations for each organ. As occurs with any other nutrients, minerals can cause toxicity if ingested in high levels or for long periods.

Minerals are nutrients involved in a high number of metabolic pathways, and it is largely accepted that many of their functions are still not well understood. Macroelements are expressed as a percentage of feeds or tissues, and are mostly involved in structural functions. Microelements, or trace minerals, are more difficult to be assessed through analysis due to their very low concentrations in animal tissues and to the limitations in equipment and techniques. In addition to being present in very low concentrations, microelements share very few common functions. However, it is possible to generalize their primary function as catalysts of enzymatic cell systems with a very broad range of functions. In these systems, minerals are frequently associated with proteins in a fixed proportion as metalloenzymes in which interactions between minerals and proteins improve catalytic activities but also reduce protein turnover.

Mineral utilization by animals primarily depends of their absorption from the ingested feed. In the feed, minerals are found in a wide range of chemical forms. They are found as organic molecules or as part of salts of varying solubility. Supplementary sources of organic minerals in the market are still recent; however, they brought attention to a group of nutrients that have been set aside for many years as less important. The interest in organic forms include differences in availability, but also it is also related to possible improvements of their specific actions at cell level.

Organic microelements have been primarily defined by AAFCO (2000). Some definitions are: Specific Metal Amino Acid Complex, resulting from complexing a soluble metal salt with a specific amino acid; Metal Amino Acid Complex, resulting from complexing a soluble metal salt with amino acids; Metal Amino Acid Chelate, resulting from the reaction of a metal ion from a soluble salt with amino acids in a molar ratio of $1 \mathrm{~mol}$ of the metal to $1-3$ (preferably 2 ) moles of amino acids, which form coordinated bonds (molecular weight of the hydrolyzed chelate should exceed 800 Daltons); Proteinate Metal, resulting from the chelatiion of a soluble salt with amino acids and/or partially solubilized protein; Polysaccharide Metal Complex, resulting from complexing a soluble salt with a solution of polysaccharides declared as integral part of an specific complex.

The word chelate derives from the Greek "chele", which means tweezers or claw. The reasons for this definition become clear when the structure of chelates is examined. They are the result of electron sharing between a metal and a ligand. A ligand is usually an anion or a molecule, which has an atom or a pair of electrons with available valences. Common ligands contain oxygen, nitrogen, sulfur, halogens, or a combination of these due to their electronic structure. Chelated minerals have non-metallic ligands, and are therefore organic. Atoms, which are able to donate their electrons, are called donor atoms. Ligands with only one donor atom are called monodented, whereas those with two or more are called polydents. Only polydents are able to form chelates, since they can bind a metal within their electronic dents or claws.

Di- or trivalent metals are well-adapted to form coordinated bonds, which are characteristic of chelates. A coordinated bond, also known as complex bond, consists of a metal and a ligand aligned in such a way that the available electrons from the donor atoms are very close to those from the metal. Mineral chelation is very important in the biological systems. Most enzymes require a chelated metal in their structures to become effective. Vitamins, such as vitamin B12 (cyanocobalamin), have a metal (in this case Co) complexed to a tetradent porphyrin group, nitrogen, and a pseudonucleotide. Porphyrin is also important for the chelation of iron on hemoglobin. Other groups are important in human and animal health due to their good chelating abilities. This is the case of EDTA (ethylenediaminetetracetic acid), which is a hexadent ligand used for the removal of heavy metals from animal tissues. Independently of their international classification, there are several characteristics that are important for the effectiveness of mineral chelates in the animal body. There are many research studies on chelates that have amino acids as ligands, whereas less is known on chelates using polysaccharides or other ligands with large molecular weights.

\section{Mineral utilization by poultry}

Trace minerals have traditionally been supplemented in broiler feeds by the use of saline sources, which cost is usually very low. Saline sources are not frequently subjected to technical criticism as to their quality, especially because they are required in very low amounts and are found as components of other feed 
ingredients. Variable availability, as well as the presence of contaminants, are important considerations when supplementing trace minerals. For instance, zinc oxide and copper sulfate are sources commonly utilized in animal feeding, but as they are often derived from residues of the steel industry, they can potentially carry high levels of contaminants, such as cadmium, fluorine, and lead to the feed. Market regulations, such as those issued by the European Union (CEC, 1999), have added new concerns into the meat production business with extended limitations in terms of heavy metals and other contaminants in animal feeds.

The determination of trace mineral requirements has also been a secondary concern in poultry nutrition as compared to other nutrients. Minerals have, however, a series of limitations in terms of utilization by animals. Source solubility and previous nutritional status of the animals are extremely important factors when measuring mineral requirements. Investigations on mineral requirements should take in account their physiological functions within the biological systems where they are expected to work. Those functions can be generally divided in construction and maintenance of hard and soft tissues, as well as in the regulation of biological processes (Underwood, 1977). The greatest contributions of macro minerals, such as calcium, phosphorus, and magnesium, are expected in hardening bones and teeth by the formation of complex inorganic matrices. Therefore, ash percentage in bones is used as corresponding measurement of $\mathrm{Ca}$ and $\mathrm{P}$ requirement levels. Soft tissues, however, also have large contributions from minerals, such as zinc, in addition to phosphorus, magnesium and sulfur. In the regulation of biological processes, essential minerals function as catalysts in enzymatic and hormonal systems as integral components of metalloenzymes, but they can also activate metalloenzymes.

Organic equilibrium needs also to be taken in consideration in each substances formed from minerals, especially trace minerals. These measurements are usually more difficult to be made as compared to live performance parameters and must involve metalloenzyme levels and other organic substances, which are usually in the form of chelates.

Mineral absorption can suffer may interferences, such as mutual antagonisms, which potentially reduce absorption and metabolism rates of some minerals. These interrelationships are traditionally expressed as shown in Figure 1, which simplifies how the interactions among minerals can potentially affect each other. Insoluble precipitates can be formed through the competition with organic and inorganic ligands. Examples are phytic acid and phosphates. Both can reduce or completely inhibit mineral availability (Cabell and Earle, 1965; Vohra et al., 1965). Phytates reduce zinc uptake (Hempe \& Cousins, 1989) and calcium impairs the absorption of copper and zinc (Lowel et al., 1994; Wedekind et al., 1994). Copper and molybdenum are strongly antagonic, whereas manganese and iron compete for similar absorption mechanisms. Manganese supplementation to solution containing iron depresses iron intake (Sandstrom, 1992). It was demonstrated that phytase supplementation improves trace mineral availability in monogastric animals; however, action of this enzyme can be limited by dietary calcium level (Angel et al., 2002).

Ashmead (1993a) summarized six groups of interactions that actively interfere with mineral absorption. Firstly, mineral absorption requires previous solubilization of the original mineral source in the intestinal lumen. Ionized metals can be further transported through the cell membrane using protein carriers. This process is $\mathrm{pH}$-dependent, and therefore, the acidic environment in the proventriculus improves solubilization, whereas the neutral or alkaline $\mathrm{pH}$ of the small intestine reduces it. Solubilized metals in the gastric environment can potentially form insoluble precipitates in their course through the small and large intestine. The presence of active ligands, such as phytic acid, can intensify the formation of precipitates. This situation is significant in high phytate diets, such as those with high levels soybean meal or rice bran, and can strongly affect minerals availability. Phytate content is very variable in soybeans and can reach values as high as 3\% in soybean meals (Cheryan, 1980; Mason et al., 1992).

Competition for the same or similar carriers is a major interference source when metals are transferred from the lumen into the enterocyte (Hill \& Matrone, 1970). Carriers are small proteins, which bear high capacity of chelating free cations present in the intestinal solution when proceeding to transport. Therefore, physical-chemical competition between cations can potentially involve micro or macro minerals or both (Starcher, 1969). The competition between iron and copper is typical: they share at least two membrane proteins, transferrin and metalotionein. Excessive copper bound to those protein may lead to iron deficiency (El Shobaki \& Rummer, 1979).

Heavy metals play a different role in antagonizing mineral absorption. Lead, for instances, inhibits the 
enzymatic synthesis of carrier proteins, e.g., the porphyrin fraction of hemoglobin, inducing anemia (Hoffbrand \& Konopka, 1977). In other situations, the replacement of one metal by another in metalloenzime molecule modifies their efficiency (Ashmead, 1993a). After being absorbed by the enterocyte, some metals return to the intestinal lumen by excretion or mucosal sloughing and resume the competition for carrier proteins. One last possibility of interference in mineral absorption is related to the impact of reduced uptake of one specific metal on the cascade reactions involved in the uptake of other minerals (Ashmead, 1993a).

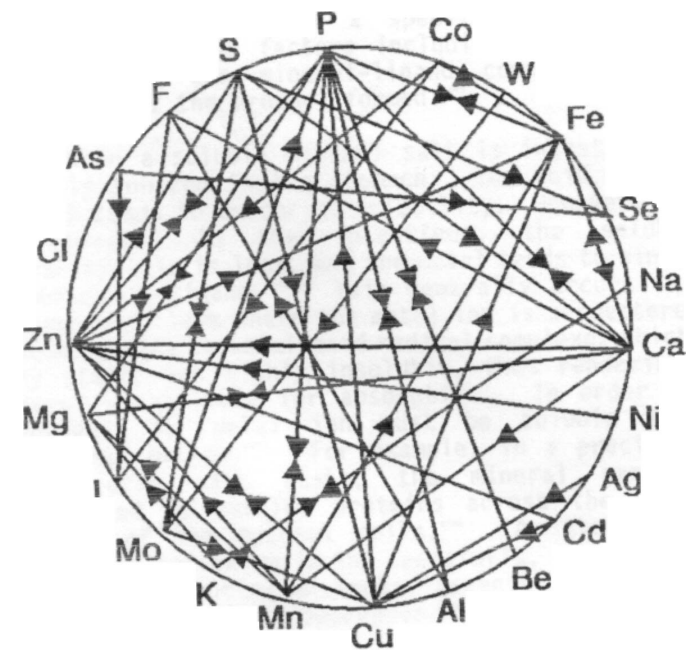

Figure 1 - Potential interrelationships between minerals in intestinal lumen and metabolism.

With a few exceptions, mineral absorption depends on the capacity of the elements to bind to transport proteins present in the enterocyte membrane. Bound minerals are then transported into the cell cytoplasm through passive diffusion or active transport. Mineral absorption can occur in any region of the intestines, but metals are usually absorbed in the duodenum provided ions are still soluble after gastric treatment (Ashmead, 1993b). As stated before, any factor antagonizing the metal capacity to bind to the ligand will reduce its absorption. Each mineral absorption rate varies with its chemical source; therefore, it is not possible to establish a single absorption rate that would fit all metals (Ashmead, 1985). Chemical reactions between the metal present in the diet and any other dietary component are directly related with their degree of absorption. Similarly, there is more than one single mechanism available for the absorption of each metal, which also depend on its chemical form at the moment of contact with the intestinal mucosa.
Metal amino acid chelates are chemically inert due to the covalent and ionic bonds between the mineral and the ligand, and therefore are not affected by factors that lead to precipitation, as it happens to minerals ionized after salt solubilization (Ashmead, 1993b). Due to their stability and small size, most chelated minerals are not altered during their passage through the digestive tract, and are completely absorbed with no break down of their amino acids. Some minerals can be chelated to two or three amino acids and absorbed as di or tripeptides. After absorption, the final separation of the metal from the amino acid is expected only when the final physiological site is reached. Therefore, chelated minerals are absorbed and transported as integral part of an organic molecule until effectively used (Ashmead, 1993b).

Nutritional body balance of each specific mineral can directly affect the absorption of this very same mineral (Patton, 1997). Differences between zinc bioavailability may not be evident until its level in the diet becomes limiting (Rojas et al., 1994). Under normal dietary supply, the passage of zinc through the enterocyte membrane depends on a carrier that is associated with it; however, rate of absorption is highly increased under zinc depletion (Menard \& Cousins, 1983). Zinc previous nutritional status influences the genetic transcription of metallothionein (Sullivan \& Cousins, 1997).

\section{Performance of poultry fed chelated minerals}

Mineral chelates have been the subject of a growing number of investigations in the past few years. Results demonstrate a clear trend for a better utilization and higher bioavailability for this type of mineral supplements. Differences between traditional trace mineral sourcesare due to the salt source and, at least for zinc and copper, oxides have minimal contribution for poultry and swine (Baker et al., 1991; Cromwell et al., 1989; Han \& Baker, 1993). Therefore, evaluations aiming at comparing metal chelates to salts should target those that present higher availability, such as sulfates.

Other dietary constituents play important roles when comparisons between chelates and salts are made. For instance, it is well known that phytate seize positive charged metals and, consequently high phytate diets tend to confound the effects of the salt sources being tested. Zinc-methionine supplemented to cornsoybean meal diets presented $206 \%$ bioavailability, but only $117 \%$ when included in a purified diet without 
phytate (Wedekind et al., 1992). In all-vegetable feeds, which bear a high proportion of phytate, the advantage of mineral chelates tends to be easier observed as compared to diets with animal by-products inclusion.

Another confounding effect that appears when metal salt sources are compared result from the simultaneous interferences of metals with similar charge. Broilers receiving excess inorganic zinc accumulate a higher proportion of zinc in their tissues, and seem to present reduced iron turnover, as well as lower iron and copper concentrations in the liver and pancreas, and lower iron in tibia (Stahl et al., 1989).

Patton (1997) suggested that the use of mineral chelates should made after further observations of their actions on animal metabolism. The mere observation of their digestibility and absorption may not allow a correct understanding of their influence on metabolism. In fact, the determination of nutrient requirements is directly related to the type of response. Weight gain and feed conversion are traditionally measured when nutrient requirements are studied; however, micronutrient evaluations should also take in consideration cell involvement for fuller understanding of their effects.

Mineral chelates are currently more expensive than the traditional mineral supplements. However, there are indications that, at least in some situations, chelated minerals can achieve biological objectives better than inorganic sources (Patton, 1997). For instance, it is known that di- and tri-peptides are absorbed faster than free amino acids. Therefore, it could be considered that amino acids and small peptides are completely absorbed, and this is likely to have an effect on their physiological function.

Bone matrix is composed mostly of collagen, and skeletal mineralization is dependent on adequate collagen growth and final quality. Zinc, manganese, and copper, as well as vitamins (e.g., ascorbic acid), are directly related with bone matrix formation. Turkey diets supplemented with zinc and manganesemethionine improved feed conversion, and also reduced mortality and leg abnormalities (Ferket et al., 1992). These diets had trace minerals in levels considered adequate (80 ppm zinc and $120 \mathrm{ppm}$ manganese as sulfates), but there were improvements when 20 and 40 ppm zinc and manganese-methionine were supplemented.

There are few long-term investigations with organic mineral sources in literature, especially targeting broiler breeders. In broiler breeder studies conducted for short periods (21 to 43 weeks of age), Barber et al. (2002) did not find any response when 150 ppm zinc sulfate was compared to the simultaneous use of zinc sulfate and zinc-amino acid. Hudson et al. (2004a) simultaneously supplemented zinc-amino acid and zinc sulfate, and observed eggshell improvements that led to the production of 3.6 extra chicks at the end of the laying period. Differences in total hatching period and chick weight at hatching were not observed (Hudson et al., 2004b). Reduced early broiler mortality was found when zinc and manganese-amino acid were supplemented to broiler breeders throughout the laying period (Virden et al., 2003). Recently, Tako et al. (2004) observed that injecting zinc-methionine in ovo at 17 days of incubation led to improvements in the morphological development and intestinal mucosa enzyme expression of hatching chicks.

Zinc benefits of on animal immunity were shown in the past (Chevalier et al., 1996). Zinc-methionine usually has higher bioavailability than inorganic sources, and can be absorbed in its intact form, therefore potentially altering zinc balance in metabolism. Independently of the involved mechanisms, improvements were shown in some cell functions related to disease resistance when zinc-methionine was supplemented in broiler or breeder feeds (Kidd, 1996). Dietary supplementation with zinc and manganese chelates, when inorganic inclusions of these minerals where considered adequate, led to immune improvements in turkeys (Ferket \& Qureshi, 1992). Disease resistance and the transference of antibodies to progeny can be improved when broiler breeders are fed zinc-amino acid alone or combined with zinc sulfate (Hudson et al., 2004a). Synergistic effects are also expected when zincmethionine is fed along with vitamin E. Cells deficient in zinc present better membrane structure when vitamin $E$ levels higher than the traditionally used are supplemented to broilers (Bettger et al., 1980). Protection against peroxidation and as well as better cell membrane integrity are the proposed modes of action of zinc during animal immune response. Skin scratches and other skin damages are frequent in broilers. Escherichia coli often invades the damaged skin tissue, leading to the development of cellulitis and to condemnation in processing plants. Mackling et al. (2000) observed improvements in the response to cellulitis-infected birds when higher vitamin $E$ levels were added to the feed. Downs et al. (2000) found a synergistic effect when supplementing 48 IU vitamin $\mathrm{E}$ combined with 40 ppm zinc-amino acid in the same 
feed, with reductions in cellulitis incidence and severity in broilers.

Studies with swine tend to show similar results as those found in broilers. Coffey et al. (1994) observed improvements in piglet performance when copperlysine was used as compared with copper sulfate. On the other hand, Apgar et al. (1994) did not verify any response of this combination in growth. Hill et al. (1986) found higher feed intake with the use of zincmethionine, but feed conversion was not influenced when that chelate was combined with copper sulfate. Higher nominal zinc absorption was found by Hill et al. (1987) for zinc-methionine as compared to zinc chloride, suggesting differences in transport rates between these two sources.

\section{CONCLUSIONS}

Chelated minerals are increasingly used in animal nutrition. Growing restrictions to the use of antibiotics create opportunities to more public-friendly nutritional additives that can also improve performance, but using a different pathway. Mineral chelates have a different involvement in metabolism as compared to inorganic sources, promoting, among other benefits, better mineral uptake and enhancement of the immune response. These benefits of supplemental mineral chelates may resemble those already obtained with other organic minerals present in natural sources, such as iron in hemoglobin and cobalt in vitamin B12. The formulation of diets targeting precision nutrition will eventually demand the extensive use of mineral chelates, which could be added to the feeds to promote specific animals responses.

\section{REFERENCES}

Angel R, Tamim NM, Applegate JT, Dhandu AS, Ellestad LE. Phytic acid chemistry: influence on phytin-phosphorus availability and phytase efficacy. Journal of Applied Poultry Research 2002; 11:471480.

Apgar GA, Komegay ET, Linderman MD. Effect of copper lysine chelate and copper sulfate as growth promotants for weanling swine. Journal of Animal Science 1994; 72(Suppl1):273.

Ashmead HD. Comparative intestinal absorption and subsequent metabolism of metal aminoacid quelates and inorganic metal salts. In: Ashmead HD, editor. The roles of aminoacid quelates in animal nutrition. Westood: Noyes Publications; 1993b.

Ashmead HD. Factors which affect the intestinal absorption of minerals. In: Ashmead HD, editor. The roles of aminoacid quelates in animal nutrition. Westood: Noyes Publications; 1993a.
Ashmead HD. Intestinal absorption of metal ions and chelates. Springfield: Charles C. Thomas; 1985. p.13-26.

Baker DH, Odle J, Funk MA, Weilan TM. Research note: bioavailability of copper in cupric oxide, cuprous oxide, and in a copper-lysine complex. Poultry Science 1991; 70:177-179.

Barber SJ, Virden WS, Ward TL, Johnson AB, Zumwalt CD, Kidd MT, McDaniel CD. Broiler breeder reproductive performance as affected by availazinc and availamanganese. Poultry Science 2002; 81(Suppl 1):119.

Bettger WJ, Reeves PG, Savage JE, O'Dell BL. Interaction of zinc and vitamin $E$ in the chick. Proceedings of the Society for Experimental Biology and Medicine 1980; 163:432-436.

Cabell CA, Earle IP. Additive effect of calcium and phosphorus on utilization of dietary zinc. Journal of Animal Science 1965; 24:800806 .

CEC - Council Directive 1999/29/EC on the undesirable substances and products in Animal nutrition. Official Journal of the European Communities 1999; 29(L115):32-46.

Cheryan MP. Phytic acid interactions in food systems. CRC Critical Reviews in Food Science and Nutrition 1980; 13:297-335.

Chevalier P, Sevilla R, Zalles L, Sejas E, Belmonte G. Effects of zinc supplementation on nutritional immune deficiency. Nutrition Research 1996; 16:369-379.

Coffey RD, Cromwell GL, Monegue HJ. Efficacy of a copper-lysine complex as a growth promotant for weanling pigs. Journal of Animal Science 1989; 72:2880-2886.

Cromwell GL, Stahly TS, Monegue HJ. Effects of source and level of copper on performance and liver copper stores in weanling pigs. Journal of Animal Science 1989; 2996-3001.

Downs KM, Hess JB, Macklin KS, Norton RA. Dietary zinc complexes and vitamin $E$ for reducing cellulites incidence in broilers. Journal of Applied Poultry Research 2000; 9:319-323.

El-Shobaki F, Rummer W. Binding of copper to mucosal transferring and inhibition of intestinal iron absorption in rats. Research in Experimental Medicine 1979; 174:187-195.

Ferket PR, Nicholson L, Robertson KD, Yoong CK. Ffect of level of inorganic and organic zinc and magnesium on the performance and leg abnormalities of turkey toms. Poultry Science 1992; 71(Suppl 1):60.

Ferket PR, Qureshi MA.Effect of level of inorganic and organic zinc and manganese on the immune function of turkey toms. Poultry Science 1992; 71(Suppl.1):60.

Haas E, editor. Feed ingredients definitions. Harrisburg: Association of American Feed Control Officials; 2000.

Hahn M, Baker DH. Growth and plasma zinc response of young pigs fed pharmacologic levels of zinc. Journal of Animal Science 1993; 68:3020-3024. 
Hempe JM, Cousins RJ.Effect of EDTA and Zinc-methionine complex on zinc absorption by rat intestine. Journal of Nutrition 1989; 119:1179-1187.

Hill $\mathrm{CH}$, Matrone $\mathrm{G}$. Chemical parameters in the study of in vivo and in vitro interactions of transition elements. Federation Proceedings 1970; 29:1474-81.

Hill DA, Peo ER, Lewis AJ, Crenshaw JD. Zinc amino acid complexes for swine. Journal of animal Science 1986; 63:121-130.

Hill DA, Peo ER, Lewis JA. Effect of zinc source and picolinic acid on Zn uptake in an in vitro continuous-flow perfusion system for pig and poultry intestine segments. Journal Nutrition 1982; 177:17041707.

Hoffbrand A, Konopka L. Haem synthesis in sideroblastic anemia. In: Porter R, Fitzsimons D, editors. Iron metabolism. Amsterdam: Elsevier; 1977.

Hudson BP, Dozier WA, Wilson JL. Sander JE, Ward TL. Reproductive performance and immune status of caged broiler breeder hens provided diets supplemented with either inorganic or organic sources of zinc from hatching to 65 wk of age. Journal of Applied Poultry Research 2004a; 13:349-359.

Hudson BP, Fairchild BD, Wilson JL, Dozier WA, Buhr RJ. Breeder age and zinc source in broiler breeder hen diets on progeny characteristics at hatching. Journal of Applied Poultry Research 2004b; 13:55-64.

Kidd MT, Ferket PR, Qureshi MA. Zinc metabolism with especial reference to its role in immunity. World's Poultry Science Journal 1996; 52:309-324.

Lowel JA, Wiseman J, Cole DJA. Absorption and retention of zinc when] administered as an amino-acid chelate in the dog. Journal of Nutrition 1994; 124:2572-2574

Macklin KS, Norton RA, Hess JB, Bilgili SF. The effect of vitamin E on cellulitis in broiler chickens experiencing scratches in a challenge model. Avian Diseases 2000; 44:701-705.

Mason AC, Weaver CM, Kimmel S, Brown RK. Effect of soybean phytate ontent on calcium bioavailability in mature and immature rats. Journal of Agriculture and Food Chemistry 1992; 246-249.

Menard MP, Cousins, RJ. Zinc transport by brush border membrane vesicles from the rat intestine. Journal of Nutrition 1983; 113:1434-1442.

Patton R. Efficacy of chelated minerals: review of literature. Proceedings of the $2^{\text {nd }}$ Conference of the Nutrition Advisory Group of the American Zoo and Aquarium Association on Zoo and Wildlife Nutrition; 1997 16-19 out; Ft. Worth, Texas. EUA; 1979. p.14-31.

Rojas LX, McDowell LR, Cousins RJ, Martin FG, Wilkinson NS, Johnson $A B$. Relative bioavailability of zinc methionine and two inorganic zinc sources fed to cattle. Journal of Animal Science 1994; 72(Suppl):95.

Sandstrom B. Dose dependence of zinc and magnesium absorption in man. Proceedings of the Nutrition Society 1992; 51:211-218.
Stahl JL, Greger JL, Cook ME. Zinc, copper, and iron utilization by chicks fed various concentrations of zinc. British Poultry Science 1989; 30:123-134.

Starcher BC. Studies on the mechanism of copper absorption in the chick. Journal of Nutrition 1969; 97:321-326.

Sullivan VK, Cousins RJ. Competitive reverse transcriptionpolymerase chain reaction shows that dietary zinc supplementation in humans increases monocyte metallotionine mRNA levels. Journal of Nutrition 1997; 127:694-698.

Tako E, Ferket PR, Uni Z. Zinc-methionine enhances the intestine development And functionality in the late term embryos and chicks. Poultry Science 2004; 83(Suppl):267.

Underwood EJ, Suttle NF. Mineral nutrition of livestock. New York: CAB International; 1999.

Underwood EJ. Trace elements in human and animal nutrition. New York: Academic Press; 1977.

Virden WS, Yeatman JB, Barber SJ, Zumwalt CD, Ward TL, Johnson $A B$, Kidd MT. Hen mineral nutrition impacts progeny livability. Journal of Applied Poultry Research 2003; 12:411-416.

Vohra P, Gray GA, Kratzer FH. Phytic acid-metal complexes. Proceedings of the Society of Experimental Biology and Medicine 1965; 120:447-449.

Wedekind KJ, Hortin AE, Baker DH. Methodology for assessing zinc bioavailability: efficacy estimates for zinc-methionine, zinc sulfate, and zinc oxide. Journal of Animal Science 1992; 70:178-187.

Wedekind KJ, Lewis AJ, Giesmann MA, Miller PS. Bioavailability of zinc from inorganic and organic sources for pigs fed corn-soybean meal diets. Journal of Animal Science 1994; 72:2681-2689. 